International Journal of Canadian Studies

Revue internationale d'études canadiennes

\title{
Le transculturalisme : de l'origine du mot à « l'identité de la différence » chez Hédi Bouraoui
}

\section{Angela Buono}

Numéro 43, 2011

Miscellaneous: International Perspectives on Canada

En vrac : perspectives internationales sur le Canada

URI : https://id.erudit.org/iderudit/1009452ar

DOI : https://doi.org/10.7202/1009452ar

Aller au sommaire du numéro

\section{Éditeur(s)}

Conseil international d'études canadiennes

\section{ISSN}

1180-3991 (imprimé)

1923-5291 (numérique)

Découvrir la revue

\section{Citer cet article}

Buono, A. (2011). Le transculturalisme : de l'origine du mot à « l'identité de la différence " chez Hédi Bouraoui. International Journal of Canadian Studies / Revue internationale d'études canadiennes, (43), 7-22.

https://doi.org/10.7202/1009452ar

\section{Résumé de l'article}

Cette étude illustre quelques implications de la notion du transculturel, tout en la situant par rapport aux notions du pluriculturel, de l'interculturel et du multiculturel. Depuis sa première apparition en 1940 dans le domaine anthropologique, la notion de transculturalisme a élargi son champ d'application en tant que méthode d'interprétation potentielle de toute réalité métissée. Cependant, au niveau social et politique, l'approche transculturelle demeure théorique, voire utopique, ainsi que l'a démontré l'expérience québécoise du groupe d'intellectuels rassemblés de 1983 à 1997 autour du magazine Vice Versa. C'est au niveau identitaire et esthétique que le transculturalisme trouve son plein accomplissement dans l'expérience personnelle et poétique de l'écrivain franco-ontarien d'origine tunisienne Hédi Bouraoui. En insistant sur l'idée de traversée, de passage et d'échange entre les cultures, il érige la migrance en valeur identitaire et en principe de création littéraire : si « l'émigration redéfinit l'ontologie de l'être contemporain », les notions d'identité et de différence - les deux pivots du transculturalisme tel que Bouraoui le conçoit - en sont également renouvelées par la démarche transculturelle et transpoétique que l'auteur applique à son écriture et à sa conception de la culture. L’identité et la différence sont analysées et redéfinies jusqu'à en renverser la valeur signifiante. La relation d'opposition entre les deux termes se tourne en identification : « l'identité de la différence » introduit une perspective nouvelle dans l'évaluation de la diversité, tout en lui conférant une qualité oxymorique qui demeure au fond de la poétique bouraouienne et se pose en clé de lecture d'une appartenance identitaire à même de résoudre les contradictions de la pluralité en unicité originale et harmonieuse.
All Rights Reserved @ Conseil international d'études canadiennes, 2012
Ce document est protégé par la loi sur le droit d'auteur. L’utilisation des services d'Érudit (y compris la reproduction) est assujettie à sa politique d'utilisation que vous pouvez consulter en ligne.

https://apropos.erudit.org/fr/usagers/politique-dutilisation/ 


\title{
Angela Buono
}

\section{Le transculturalisme : de l'origine du mot à "l'identité de la différence " chez Hédi Bouraoui}

\section{Résumé}

Cette étude illustre quelques implications de la notion du transculturel, tout en la situant par rapport aux notions du pluriculturel, de l'interculturel et du multiculturel. Depuis sa première apparition en 1940 dans le domaine anthropologique, la notion de transculturalisme a élargi son champ d'application en tant que méthode d'interprétation potentielle de toute réalité métissée. Cependant, au niveau social et politique, l'approche transculturelle demeure théorique, voire utopique, ainsi que l'a démontré l'expérience québécoise du groupe d'intellectuels rassemblés de 1983 à 1997 autour du magazine Vice Versa. C'est au niveau identitaire et esthétique que le transculturalisme trouve son plein accomplissement dans l'expérience personnelle et poétique de l'écrivain franco-ontarien d'origine tunisienne Hédi Bouraoui. En insistant sur l'idée de traversée, de passage et d'échange entre les cultures, il érige la migrance en valeur identitaire et en principe de création littéraire : si "l'émigration redéfinit l'ontologie de l'être contemporain », les notions d'identité et de différence - les deux pivots du transculturalisme tel que Bouraoui le conçoit - en sont également renouvelées par la démarche transculturelle et transpoétique que l'auteur applique à son écriture et à sa conception de la culture. L'identité et la différence sont analysées et redéfinies jusqu'à en renverser la valeur signifiante. La relation d'opposition entre les deux termes se tourne en identification : "l'identité de la différence » introduit une perspective nouvelle dans l'évaluation de la diversité, tout en lui conférant une qualité oxymorique qui demeure au fond de la poétique bouraouienne et se pose en clé de lecture d'une appartenance identitaire à même de résoudre les contradictions de la pluralité en unicité originale et harmonieuse.

\begin{abstract}
This study illustrates a few of the implications of our notion of transcultural, while situating it in relation to notions of pluricultural, intercultural and multicultural. Since it first appeared in 1940 in the field of anthropology, the notion of transculturalism has expanded its application as a potential interpretive method of all hybridized realities. However, at the social and political level, the transcultural approach remains theoretical, utopic even, as demonstrated by the Québécois experience of a group of intellectuals who were together from 1983 to 1997 for the magazine Vice Versa. It is in terms of identity and aesthetics that transculturalism becomes fully accomplished in the personal and poetic experience of Hédi Bouraoui, a Franco-Ontarian writer originally
\end{abstract}


from Tunisia. By insisting on the idea of crossing, of passage, and of exchange between cultures, he uplifts migrance to a value of identity and a principle of literary creation: if "emigration redefines the ontology of the contemporary self", notions of identity and difference-the two linchpins of transculturalism as conceived by Bouraoui-are equally renewed by the transcultural and transpoetic approach that the author applies to his writing and his idea of culture. Identity and difference are analyzed and redefined to the point of overturning the signifier value. The oppositional relationship between the two terms becomes one of identification: "the identity of difference" introduces a new perspective in the evaluation of diversity, gives it an oxymoronic quality which remains at the depth of Bouraoui's poetics, and unlocks the reading of identity belonging while it resolves contradictions of plurality into a uniqueness that is original and harmonious.

La notion du transculturel fait désormais partie du langage courant, ainsi qu'en témoigne l'inclusion du terme dans les principaux dictionnaires. Néanmoins, les définitions qu'ils en donnent ne rendent pas tout à fait compte des implications du mot. Si dans Le Grand Robert l'on indique de façon générique que transculturel c'est ce « qui concerne les transitions entre cultures différentes » (ad vocem), dans Le Petit Larousse l'idée même de mouvement et de passage entre les cultures est ramenée à la simple pluralité culturelle. Dans l'édition de 2003 on peut lire que transculturel c'est ce « qui concerne les relations entre plusieurs cultures » (ad vocem), tandis que dans une édition plus récente du dictionnaire en ligne (2009) on trouve la définition suivante : " se dit d'un phénomène social qui concerne plusieurs cultures, plusieurs civilisations différentes » (ad vocem).

Cette dernière formulation n'apporte guère davantage de précisions sur la spécificité du transculturel et, qui plus est, ces définitions ne permettent point de bien démarquer le transculturel des notions voisines du pluriculturel, de l'interculturel et du multiculturel. Pour ce faire, il convient de se rapporter aux définitions proposées par le Conseil de l'Europe. Dans le Cadre européen commun de référence pour les langues, la dimension pluriculturelle est définie en ces termes :

Les différentes cultures (nationale, régionale, sociale) auxquelles quelqu'un a accédé ne coexistent pas simplement côte à côte dans sa compétence culturelle. Elles se comparent, s'opposent et interagissent activement pour produire une compétence pluriculturelle enrichie et intégrée dont la compétence plurilingue est l'une des composantes, elle-même interagissant avec d'autres composantes. (p. 12) 
Il s'ensuit, ainsi que les commentateurs l'ont bien remarqué, que « le plurilinguisme et le pluriculturalisme correspondent à une spécificité personnelle mobilisée dans une situation de communication » (Bernaus et al. 12), là où le multiculturalisme et l'interculturalisme relèvent d'une dimension collective et sociétale. En ce qui concerne le premier, « il convient [...] de conserver les termes multilinguisme et multiculturalisme à la description de contextes mettant en contact différentes langues et cultures » (Bernaus et al. 12), tandis que « l'interculturalité est un terme qui désigne tout d'abord une situation de communication dans laquelle les participants mobilisent toutes leurs capacités pour interagir les uns avec les autres » (Bernaus et al. 13).

Les notions de pluriculturel, de multiculturel et d'interculturel font donc appel de façon respective à l'individu, au groupe et à la situation de communication : le transculturel se pose en point de convergence et dépassement de ces fondements, en processus dynamique entraînant une transmutation foncière de ses données de base par le biais de leur profonde interpénétration.

\section{De l'origine du mot transculturel}

Afin de bien saisir la prégnance de la notion de transculturel, il convient d'en retracer l'évolution. On fait remonter sa naissance à la réflexion de l'anthropologue cubain Fernando Ortiz : en 1940, dans son ouvrage Contrapunteo cubano del tabaco y el azúcar, il introduit le mot " transculturation » en substitution du terme « acculturation », pour mieux rendre compte de la complexité ethnique et de l'évolution ethnoculturelle dans l'île de Cuba ${ }^{1}$ Ainsi que l'a expliqué Jean Lamore :

À cette époque, la notion d'acculturation est très en vogue : chère aux Nord-Américains, elle débouche sur l'idée d'assimilation [...] : fondée sur un fait éminemment eurocentriste, elle impliquait que l'indigène, le « sauvage », le « barbare » devait obligatoirement « s'assimiler », ou encore « se civiliser ». Or, Ortiz, en étudiant le processus de formation ethnoculturelle de Cuba, définit un processus totalement différent : la transculturation, qui se caractérise par le choc. L' « ex-culturation » des peuples conquis, soumis ou exploités, n'empêche pas certains syncrétismes : le conquérant prend lui aussi une part de sa culture. Il y a aussi " inculturation », c'est-à-dire une acquisition réciproque d'éléments culturels. (p. 45)

Tout en dépassant la perspective eurocentrique dominante, le néologisme imaginé par Ortiz résume les implications multiples des transferts culturels, comme ce passage, ici rapporté dans la traduction qu'en offre Jean Lamore, met bien en évidence :

Le vocable " transculturation » exprime mieux les différentes phases du processus de transition d'une culture à l'autre, car 
celui-ci ne consiste pas seulement à acquérir une culture distincte - ce qui est en toute rigueur ce qu'exprime le mot anglo-américain d' " acculturation »- mais que le processus implique aussi nécessairement la perte ou le déracinement d'une culture antérieure, - ce qu'on pourrait appeler " déculturation », et en outre, signifie la création consécutive de nouveaux phénomènes culturels que l'on pourrait dénommer «néo-culturation ». [...] Dans l'ensemble le processus est une transculturation, et ce vocable renferme toutes les phases de sa parabole (Lamore 44).

Bronislaw Malinowski, dans son introduction au Contrapunteo d'Ortiz, saisit toute la valeur innovante de la transculturation, ainsi que sa charge transformationnelle de création :

Es un proceso en el cual emerge una nueva realidad, compuesta y compleja; una realidad que no es una aglomeración mecánica de caracteres, ni siquiera un mosaico, sino un fenómeno nuevo, original e independiente [...] una transición entre dos culturas, ambas activas, ambas contribuyentes con sendos aportes, y ambas cooperantes al advenimiento de una nueva realidad de civilización (Ortiz 5).

Depuis, par suite de ce pouvoir de création dont il est porteur, le transculturel a dépassé les limites du domaine d'application d'origine pour élargir son champ d'action en tant que méthode d'interprétation potentielle de toute réalité métissée. Nous nous bornerons ici à en examiner les implications identitaires et littéraires dans l'interprétation toute particulière qu'en donne l'écrivain franco-ontarien d'origine tunisienne Hédi Bouraoui, qui nous paraît avoir exploité les potentialités du transculturel jusqu'à leur plein épanouissement. Pour mieux faire ressortir son approche originale, nous nous arrêterons brièvement sur l'expérience québécoise des fondateurs du magazine transculturel Vice Versa, desquels Bouraoui s'était un temps rapproché2 pour poursuivre ensuite sa réflexion individuelle sur le transculturel en tant que principe de création poétique.

\section{Du sens politique du transculturel}

Au Québec, l'application du transculturel à l'expérience migrante a été le fait, au cours des années quatre-vingt et quatre-vingt-dix du siècle dernier, du groupe d'intellectuels d'origine italienne rassemblés autour du magazine Vice Versa, proposant un projet transculturel dont Fulvio Caccia et Lamberto Tassinari ont été les porte-parole :

Le terme transculturel a une dimension politique car ce mot implique la traversée d'une seule culture en même temps que son dépassement. L'unité qu'il sous-tend n'a pas la même résonance que celle qu'évoquent le termes « inter-culturel» ou « multi-culturel». Ceux-ci définissent un ensemble et le circonscrivent dans un espace et un temps, 
alors que le transculturel ne possède pas de périmètre. C'est le passage et l'implication totale à travers et au-delà des cultures (Caccia, Sous le signe 299).

La dimension transversale au niveau du temps et de l'espace du projet transculturel tel que le conçoivent les intellectuels italo-québécois confère à sa portée politique un caractère utopique, se réclamant de cette " utopie nord-américaine » que Jean-Michel Lacroix et Fulvio Caccia, dans leur introduction au volume Métamorphoses d'une utopie, définissent comme l'idéal fondant « [...] une nouvelle humanité. Humanité enfin dépouillée de son eurocentrisme, débarrassée du carcan de l'Histoire, où il serait possible de réinventer la culture en saisissant l'absence, l'entre-deux qui conduit à l'altérité créatrice » (p. 12). Le caractère dichotomique du projet transculturel, partagé entre l'idéal et sa réalisation, émerge des propos de Tassinari, lors de son entrevue avec Fulvio Caccia (1985) :

Ce projet se manifestera dans sa plénitude lorsqu'il investira la sphère politique et économique. Le transculturel travaille une gestion de la société dépourvue de discrimination [...], mais il n'en demeure pas moins que le discours transculturel est au fond un discours sur le pouvoir. À la limite, il remet en question le fonctionnement de la société. [...] La transculture possède un ressort utopique qui remet en question la base traditionnelle de la société (Caccia, Sous le signe 303-304).

$\mathrm{Au}$ cours d'un séminaire international qui s'est déroulé à Rome en 2005, consacré au " Projet transculturel de Vice Versa », Tassinari a tracé le bilan de cette aventure intellectuelle en soulignant la double dimension, identitaire et sociale, de la transculture :

le trans [...], proposé par Vice Versa signifiait traversée, passage, métamorphose continue de l'identité : perte et gain sans arrêt, osmose. [...] Je ne m'arrêterai ici que sur l'aspect politique de la démarche transculturelle, cet aspect que justement Vice Versa n'a jamais réussi, en aucune mesure, à traduire en réalité sociale. Si à la base de la vision transculturelle il y a, au niveau de l'individu, la poursuite et l'acceptation d'une identité multiple, hybride, en devenir continuel, alors sur le plan politique, de la cité, à cette identité devrait correspondre une société libérée des fantasmes du pouvoir [...], enfin l'avènement d'une vraie démocratie à travers l'autonomie de l'individu. (p. 23)

Profondément enraciné dans la réalité immigrante du Québec des années quatre-vingt, le projet de Vice Versa a été conditionné dans son parcours par le contexte sociopolitique où il a pris naissance ${ }^{3}$. Cependant, son « échec productif » (p. 67), ainsi que l'a qualifié Régine Robin ${ }^{4}$, tient sans doute aussi dans sa dimension utopique ${ }^{5}$, maintes fois soulignée par Tassinari, concevant « la transculture [...] comme une forme de substitut soft de l'utopie perdue, comme sa continuation sous les formes du métissage et de l'impureté » (p. 21). 
En soulignant le but de « fonder un corps politique en dehors de toute communauté d'esprit, de langue ou de culture » (Vice Versa 33), Fulvio Caccia a formulé " l'hypothèse que la transculture est un projet pour restituer et rénover le sens originel de "civilisation" telle que la définition initiale de transculturation l'implique » (Vice Versa 34). Ainsi que l'explique l'auteur :

La civilisation se distingue [...] par le fait qu'elle suppose une hiérarchie, une décision... et renvoie directement à la civitas, la ville tandis que la culture renvoie aux champs et à une acception consensuelle et non hiérarchique qui institue le peuple en tant qu'acteur de l'histoire (Vice Versa 34).

En remontant à l'étymologie commune de deux mots, Caccia pose donc en évidence la parentèle entre la civilisation, dans son sens anthropologique, et la politique, dans son sens social. Il se rapporte en particulier à la notion dynamique de civilisation impliquée dans la transculturation décrite par Ortiz. Malinowski en avait bien souligné le pouvoir de création ethnoculturelle, un pouvoir qui, transposé dans le domaine sociopolitique, confère à la notion de transculture élaborée par l'équipe de Vice Versa le statut idéal d'un modèle du devenir humain.

\section{Du sens identitaire du transculturel}

Chez Hédi Bouraoui le transculturel accomplit une autre étape de son parcours, en manifestant sa force de création sur le double plan de l'identité et de l'esthétique. Tunisien de naissance, immigré à Toronto à la fin des années soixante après ses études en France et aux États-Unis, Hédi Bouraoui a élaboré sa notion du transculturel à partir d'une réflexion tout à fait autonome ${ }^{6}$, qu'il a entamée dès les années soixante-dix en puisant directement dans sa propre expérience de vie : par sa formation pluriculturelle et son itinéraire tricontinental, chevauchant l'Afrique, l'Europe et l'Amérique, il s'est fait lui-même carrefour culturel et incarnation vivante du transculturalisme. Son choix de s'établir au Canada a été déterminé, ainsi qu'il l'a souligné au cours d'une entrevue, par la présence d'" une société multiculturelle qui se formait et qui correspondait à [s]on héritage [...] multiple et multiculturel et multiracial et multireligieux » (Chamberland 185). Poète, écrivain et critique, Bouraoui a consacré son œuvre entière à la promotion et à la diffusion de cette notion qu'il pose en valeur humaniste fondamentale :

Nous avons défini le terme transculturalisme après avoir réfléchi sur la politique canadienne du multiculturalisme qui, d'après nous, encourageait la constitution de ghettos culturels à l'intérieur de la mosaïque canadienne. Le transculturalisme est d'abord, et avant tout, une profonde connaissance de soi et de sa culture originelle afin de la trans/cender d'une part, et de la trans/vaser d'autre part, donc la trans/mettre, à l'altérité. Ainsi se créent des ponts de compréhension, 
d'appréciation, de tolérance, de paix entre moi et les autres, la culture d'un pays à l'autre dans son intraitable différence (Transpoétique 10).

En observateur attentif de la réalité qui l'entoure et vivant dans sa chair l'expérience de la migrance dans un pays d'immigration massive, Bouraoui envisage le transculturalisme comme un développement potentiel du multiculturalisme canadien, apte à en mettre en valeur les enjeux positifs et à en déjouer l'effet secondaire du repliement des différentes communautés sur elles-mêmes :

Pour ne pas occulter l'apport positif du multiculturalisme, à savoir la reconnaissance et la validité d'autres cultures au sein d'une culture nationale, nous avons voulu détourner ce projet vers le transculturalisme qui a pour but de bâtir des ponts entre les diversités culturelles, de faire passer les valeurs d'une aire géographique à une autre. Autrement dit, une nouvelle focalisation pour que les différentes communautés se penchent sur la culture des uns et des autres (Transpoétique 63-64).

En appliquant à la culture les concepts de traversée, transition, transformation qu'entraîne la notion du transculturel, Bouraoui a élaboré une vision culturelle dynamique à même de refléter la réalité et traduire les enjeux du monde actuel. D'après lui, « l'émigration redéfinit l'ontologie de l'être contemporain » (Dotoli 56) et se pose par conséquent en valeur identitaire fondamentale - ce que Bouraoui appelle poétiquement l'émigressence ${ }^{7}$. En renversant la vision stéréotypée de l'émigration pour en dégager les valeurs potentielles, Bouraoui a érigé le phénomène migratoire en fondement de toute interaction humaine et donc de tout échange entre les cultures :

Il ne s'agit pas ici de retracer l'essence des mouvements migratoires, le déracinement, l'exil, le déchirement, l'aliénation, etc., mais plutôt d'accentuer l'émigration tacite et implicite, intérieure et actuelle, littérale et symbolique de nos propres gestes et de notre propre action : à savoir cet écart, ce déplacement, cette tension de mouvance, entre désir et réalité, intention et acte, geste et manifestation, en un mot, entre le moi qui agit sur le monde et le monde qui agit sur le moi (Pertinence 56).

Cette dynamique est à la base du processus de formation et de transformation des cultures qui s'accompagne de l'échange transculturel et que Bouraoui qualifie de « créaculture $»^{8}$, néologisme de son invention :

Si nous définissons la culture comme une interaction entre l'homme et son milieu, dans un modus operandi qui secrète les valeurs régissant une société, une nation, la créaculture met l'accent sur le côté créateur des valeurs représentant une vision unitaire où le sujet et le monde sont en perpétuelles tensions et créations vers une éventuelle harmonie. Cet équilibre précaire est à saisir par une approche interdisciplinaire, 
éclectique et essentiellement humaniste qui refuse de réduire culture et civilisation d'un pays à leur contexte purement historique, littéraire ou artistique (Transpoétique 32).

Le transculturalisme tel que Bouraoui le conçoit propose, d'un côté, une approche positive du choc des cultures, en tant que fondement d'une culture de niveau supérieur, une transculture profondément enracinée dans l'expérience migrante, et par là même, apte à en traduire les préoccupations identitaires et les solutions d'adaptation à un contexte culturel étranger; de l'autre côté, le transculturalisme se pose en modèle identitaire et en valeur humaniste traversant et dépassant toute frontière, dans le but de promouvoir un idéal éthique de tolérance et de paix qui n'est pas la moindre des implications du message bouraouien.

Pour Bouraoui la paix revêt une valeur non seulement morale, mais aussi identitaire : il énonce son idéal de tolérance et de communion entre les peuples en affirmant que « la Paix, c'est la véritable rencontre de l'Autre dans sa vérité, c'est l'acceptation totale de la différence » (Vers et l'Envers 34). Cet axiome tourne autour de la notion de différence qu'ailleurs Bouraoui formule en termes d' « identité de la différence » (Dotoli 59), à savoir la différence érigée en valeur identitaire et en source d'enrichissement culturel.

Quant à ce principe, il dérive essentiellement de son héritage culturel méditerranéen : la diversité et l'altérité sont des composantes fondamentales de l'identité méditerranéenne, tout comme les valeurs humanistes traditionnelles de l'ouverture à l'autre, du respect de l'étranger, du sens de l'accueil et du partage réciproque. La Méditerranée a été le théâtre, déjà au second millénaire avant Jésus-Christ, d'un exemple de transculturalisme avant la lettre représenté par les Phéniciens qui, en poussant leurs commerces du Proche-Orient aux Colonnes d'Hercule, fusionnaient les traditions, les cultes et les cultures des peuples rencontrés tout au long de leurs traversées de la mer'. Et plus tard dans la ville punique de Carthage en Tunisie, la terre natale de Bouraoui, se sont mélangés bon nombre de peuples d'Afrique, d'Europe et d'Asie - ce qui mène notre auteur à affirmer que pour lui : "Carthage, c'est au fait la métaphore [...] de ce qu'on appelle aujourd'hui "la mosaïque canadienne" » (Dotoli 56).

L'identité et la différence demeurent deux concepts-clés du transculturalisme bouraouien. Le rapport d'opposition entre ces deux termes est tourné en identification par la formulation qu'en donne l'auteur : l'« identité de la différence » renvoie au caractère oxymorique de toute identité humaine, dont une composante essentielle est « l'étrangeté inconnue par laquelle nous sommes tous des êtres étrangers condamnés à l'étrangeté absolue » (Bangkok blues 14). La découverte de l'autre et de la différence entraîne la prise de conscience de cette étrangeté propre à tout homme et l'approche de l'autre n'est qu'une forme particulière de migrance : 
En effet, en communiquant nous immigrons tous vers et dans les autres par la parole [...]. Ainsi nous sommes tous des immigrés, ce qui déclenche un sens d'égalité et de fraternité... Une nouvelle solidarité dans une communauté qui non seulement accepte la différence, mais va plus loin en la célébrant (Transpoétique 66).

La perspective transculturelle de Bouraoui implique une participation et une tension conscientes à l'échange entre les cultures et refuse tout phénomène de déculturation que la théorie d'Ortiz considérait comme une des étapes du processus de transculturation; de même elle se démarque de la vision du groupe de Vice Versa, qui envisageait l'identité migrante comme la manifestation d'une dynamique de « perte et gain » (Tassinari 23) entre la culture d'origine et la culture d'accueil. D'après Bouraoui, la construction de l'identité ne comporte pas de perte, mais elle se fait par addition, au fur et à mesure de la découverte de l'autre et de l'intégration de sa différence :

un poète a proclamé avec insistance qu'il faut s'anéantir pour rencontrer l'autre, différent. Non, pas se soustraire, s'additionner en restant soi-même pour être sans cesse changé, modulé. [...] Cette poussée n'est rien d'autre que [...] ce désir virulent et vertigineux de quitter notre peau, non pour l'inverser ou la masquer, mais pour lui insuffler d'autres tonalités (Bangkok blues 14).

Appliquée à la réalité canadienne, l'« identité de la différence » trouve son symbole dans un représentant de la faune du pays, l'orignal, que Bouraoui pose en illustration vivante de la diversité ethnique et culturelle du Canada. Il rappelle que « dans son Voyage en Amérique Chateaubriand le décrivait ainsi : "L'orignal a le mufle d'un chameau, le bois plat du daim, les jambes du cerf. Son poil est mêlé de gris, de blanc, de rouge, de noir" » (La Francophonie 87). Le caractère composite et mélangé des formes et du poil de l'orignal l'élève sous la plume de Bouraoui en mythe fondateur de l'identité transculturelle. Orignalitude, c'est le mot que Bouraoui a forgé pour désigner une « identité de la différence » profondément enracinée dans le terroir canadien :

Une nouvelle création conceptuelle qui retient l'origine pour y additionner les différences. [...] L'orignalitude célèbre chaque infime partie de ses diverses composantes. [...] Elle tend plutôt à abolir les frontières culturelles qui cloisonnent, non pas pour les annuler, mais pour les rendre perméables de part et d'autre, sans pour autant faire perdre ce qui fait l'originalité de chacune (Le mythe de l'orignalitude 83).

Bouraoui fait encore recours à un oxymoron pour exprimer de façon incisive le caractère pluriel de l'identité transculturelle : " Je est nôtre » (Transpoétique 42). Cette devise aux échos rimbaldiens pose une relation dialectique entre le singulier et le pluriel : l'identification des deux termes est immédiatement déjouée par le caractère intrinsèque de leur relation, impliquant l'ouverture, la transition, la transformation du singulier au pluriel. L'iden- 
tité même s'identifie à la différence sans perdre pour autant sa spécificité essentielle, le sujet s'objective tout en gardant son individualité première. Cette valeur transculturelle de la devise bouraouienne se double du caractère humaniste fondamental que l'auteur a assigné à son œuvre : " je est nôtre » renvoie à la pluralité culturelle, invite à l'approche de l'autre, à l'échange et à l'acceptation des différences; il souligne le rôle du sujet et son engagement en première personne, tout en refusant le repliement sur son particularisme et remarquant, au contraire, son appartenance à un contexte collectif. L'auteur l'affirme en toutes lettres, lorsqu'il déclare :

Et moi, Hédi Bouraoui, je dis «je est nôtre ». Je ne m'appartiens pas, j'appartiens à tout le monde [...]. Nous ne sommes plus dans la « binarité infernale », nous sommes dans la «pluralité ». [...] C'est la pluralité qui fait notre richesse. Si j'additionne ma culture maghrébine à ma culture française, à ma culture canadienne, je suis trois personnes en une, et je ne peux nier aucune partie da ma culture (Binarité s. p.).

La pluralité déjoue le risque qu'implique tout dualisme, ce qu'Hédi Bouraoui appelle la « binarité infernale », à savoir « le rapport qui s'établit entre deux pôles culturels [... et] qu'il faut déconstruire [...] parce qu'il instaure des ghettos culturels » (Falcicchio 121). Si la pluralité culturelle instaure plutôt des relations multilatérales et donc s'adapte bien au monde et à l'époque actuels, marqués par les chocs des peuples et des cultures, il n'en reste pas moins que « la pluralité implique deux risques : le risque de perdre son originalité personnelle et le particularisme d'une culture donnée» (Falcicchio 121).

« Je est nôtre ", c'est la formule pour sortir de l'impasse. Le " nôtre » n'étant qu'un élargissement $\mathrm{du}$ " je », tout risque de perte identitaire est déjoué en faveur d'un épanouissement du particularisme subjectif. C'est autour $\mathrm{du}$ « je » que tourne la pluralité, se déclinant toujours à la première personne pour remarquer comment l'échange véritable et l'interpénétration des cultures permettent à chaque sujet de garder son originalité, tout en s'enrichissant des valeurs de l'autre. Le « je » qui se fait « nôtre » assume la différence de l'autre et revêt une identité plurielle qui ne laisse pas de place aux particularismes. Le " je » qui se fait «nôtre » devient l'autre, dans un échange réciproque qui se pose en emblème de l'idéal humaniste et de la perspective identitaire dont l'écrivain est promoteur.

Cette devise intègre aussi le côté littéraire de l'identité de Bouraoui, puisque c'est tout d'abord en poète qu'il a forgé son « je est nôtre ». C'est un raccourci exemplaire de la démarche transculturelle qu'il applique à son écriture, l'expression accomplie de la valeur poiétique que le transculturel acquiert sous sa plume d'écrivain. 


\section{Du sens poétique du transculturel}

Il faut remonter à la genèse de la devise pour qu'on puisse saisir toute sa valeur représentative de la vision transpoétique et transculturelle de l'auteur : « je est nôtre » semble bien découler, par le biais d'un jeu homophonique, de « Je est un autre» (Rimbaud 200 et 202), le leitmotiv rimbaldien des Lettres du voyant.

L'invention verbale, le jeu de mots, la surprise langagière constituent un caractère marquant de l'écriture de Bouraoui. « Je est nôtre » est un exemple parfait du mouvement que l'auteur impose à la parole. La référence à un mot célèbre du passé situe la parole bouraouienne à l'intérieur d'une tradition littéraire - ce qui atteste encore une fois la valeur irremplaçable de l'héritage dont témoigne l'œuvre entière de Bouraoui, à partir de son tout premier recueil poétique, Musocktail. Cette Muse qui introduit la poésie bouraouienne n'est pas sans rappeler l'invocation aux Muses des poètes anciens; néanmoins, moulée dans une robe de cocktail, elle abdique sa fonction inspiratrice coutumière pour suggérer dès le début le caractère transpoétique, composite et mélangé, de cette poésie qui vient de naître à la croisée de la tradition et de l'innovation.

Rimbaud aussi exhortait à « demand[er] aux poètes du nouveau, - idées et formes » (p. 204) - ce qui ne l'empêchait de chanter : «j'allais sous le ciel, Muse! et j'étais ton féal » (p. 56), et d'adopter une impeccable versification classique, tout en proclamant qu'« il faut être absolument moderne» (p. 152). Un courant de sympathie rattache évidemment Hédi Bouraoui à « cet homme aux sandales de vent » (Struga 105), qu'il a célébré dans ses poèmes Variation Rimbaldienne et Rimbaud revisité (Struga 103-106).

C'est justement une relecture rimbaldienne, ce que Bouraoui a opéré en lançant sa devise transpoétique. Le passage du « Je est un autre » de Rimbaud au « je est nôtre » de Bouraoui n'est pas qu'un simple glissement phonétique, un jeu littéraire se bornant au niveau linguistique, mais il sous-tend une élaboration supplémentaire. Dans sa lettre à Paul Demeny, Rimbaud écrivait :

Car Je est un autre. Si le cuivre s'éveille clairon, il n'y a rien de sa faute. Cela m'est évident : j'assiste à l'éclosion de ma pensée : je la regarde, je l'écoute : je lance un coup d'archet : la symphonie fait son remuement dans les profondeurs, ou vient d'un bond sur la scène. (p. 202)

Le surgissement de la poésie implique donc une prise de distance : le « Je », en tant que sujet poétique, « est un autre ». L'accent n'est pas sur la qualité identitaire du « Je », mais plutôt sur le dédoublement des sujets. En effet, la relation établie par la copule souligne la superposition plutôt que l'identification du « Je » et d' « un autre ». Une telle interprétation est suggérée aussi par les mots de Rimbaud à Georges Izambard : 
[...] je me suis reconnu poète. Ce n'est pas du tout ma faute. C'est faux de dire : Je pense : on devrait dire on me pense. - Pardon du jeu de mots. Je est un autre. (p. 200)

Cette dépersonnalisation du « je » vise donc la négation de l'identité subjective en faveur d'une définition du sujet poétique englobant le même et l'autre, l'identité et la dissemblance, à l'instar d' '« un verbe poétique » que Rimbaud souhaitait « accessible [...] à tous les sens » (p. 139-140). C'est donc la multiplicité qui se dégage du discours rimbaldien comme le caractère essentiel et particulier du sujet poétique. Cette multiplicité que Rimbaud partage avec « un autre », Hédi Bouraoui la ramène tout entière au sujet par sa relecture du mot rimbaldien : « Pour Rimbaud je est autre ( (Transpoétique 42).

Une telle réinterprétation, insistant sur " cette équivalence et fusion fulgurantes du sujet à son altérité » (Transpoétique 70), acquiert une valeur essentielle pour la formulation du « je est nôtre ». Dans la devise bouraouienne c'est le caractère pluriel du « je » qui est mis en évidence plutôt que son caractère autre. Par le biais de cette lecture rimbaldienne, l'altérité est assumée dans sa dimension plurielle : «Je est Nôtre. Donc, l'individu incarne la pluralité d'autrui dans son contexte socio-culturel » (Transpoétique 65), - ce qui définit l'identité transculturelle du « sujet éclaté et pluriel conscient à la fois de sa post-modernité et de sa tradition» (Transpoétique 70).

La valeur de la tradition culturelle est une composante moins évidente, mais tout aussi fondamentale du cogito bouraouien : « je est nôtre » puisque l'identité du sujet transculturel, plurielle par définition, ne peut pas se passer de ses racines culturelles, qu'elles plongent dans le sol natal ou dans la terre d'adoption. La réitération de la première personne dans le passage du singulier au pluriel souligne que le sujet reconnaît son individualité dans la pluralité de ses héritages. « Je est nôtre » marque le moment où la superposition de cultures multiples, impliquant différences et divergences, devient transculture, sublimant la diversité en identité plurielle, pleinement assumée par le sujet.

\section{Conclusion}

Au Canada le multiculturalisme, en tant que caractéristique de la société et en tant que politique gouvernementale, a constitué le terrain fertile pour le développement d'une pensée transculturelle. Cependant, par rapport au multiculturel, cette réflexion n'a abouti qu'à l'élaboration d'un modèle utopique de société, tant chez les fondateurs de Vice Versa, avouant qu' « avoir imaginé qu'une telle société eût pu prendre forme sur les rives du Saint-Laurent fut une illusion » (Tassinari 23), que chez Bouraoui, d'après lequel « [...] la notion de multiculturalisme n'est pas opératoire, car elle ne tient pas compte du transvasement culturel entre les différentes ethnies. C'est pour cette raison que nous avons créé la notion de "transculturalisme" [...]. Mais là aussi nous 
avons à faire à une métaphore mythique idéale qui ne se reflète pas dans la réalité » (Transpoétique 116).

Ainsi que l'expérience personnelle et littéraire de l'auteur le démontre, c'est plutôt par rapport aux notions du pluriculturel et de l'interculturel que le transculturel s'épanouit de façon accomplie. Sur le plan individuel, le caractère pluriculturel de Bouraoui intègre ses appartenances multiples pour composer une identité transculturelle unique et plurielle, dont témoigne sa devise, identitaire et poétique à la fois, « je est nôtre ».

Quant au plan littéraire, si l'on considère l'écriture comme une situation de communication privilégiée où « la connaissance, la conscience et la compréhension des relations (ressemblances et différences distinctives) entre "le monde d'où l'on vient" et "le monde de la communauté cible" sont à l'origine d'une prise de conscience interculturelle » (Conseil de l'Europe 83), l'écriture de Bouraoui transcende le simple échange communicationnel entre des apports culturels différents pour donner naissance à une forme nouvelle d'expression littéraire transmutant la différence en identité cohérente et unitaire. Ses oxymorons en donnent une illustration parfaite. Le cogito bouraouien « je est nôtre » est un exemple accompli du métissage poétique : en se posant à la croisée de plusieurs univers littéraires, cette devise réalise ce que Bouraoui appelle l' « écriture interstitielle qui émigre / immigre d'une culture à l'autre. Sans complexe, sans frontière, sans transition »(Livr'errance 7). Tout en bouclant les vides entre les différents univers culturels, cette écriture édifie par son caractère fusionnel de nouvelles entités culturelles et de nouvelles formes à même de les exprimer.

Bien loin de représenter un simple exemple d'intertextualité, le cogito bouraouien relèverait plutôt de ce que Clément Moisan et Renate Hildebrand définissent comme transtextualité. Dans le cadre de l'écriture migrante au Québec, dont ils traitent dans leur essai Ces étrangers du dedans, « la transtextualité serait le transfert d'une culture littéraire à d'autres et son partage par des écrivains venus d'ailleurs et ceux d'ici » (p. 268) - ce qui implique le mouvement en tant que principe fondateur du texte littéraire et entraîne une définition du transculturel comme « [...] une résultante, car l'état d'équilibre précédent ne peut jamais, dans tout système littéraire, demeurer très longtemps. La littérature dans son ensemble obéit à une évolution » (p. 207).

Cette définition convient tout à fait au transculturalisme bouraouien en tant qu'évolution de l'individualité pluriculturelle et de la communication interculturelle. La notion d'évolution demeure aussi à la base de la perspective anthropologique d'Ortiz, puisque « la transculturation [...] n'est pas un moment, n'est pas un facteur isolé, mais bien un processus séculaire, constant, permanent » (Lamore 45). Dans le processus de formation ethnique l'évolution transculturelle revêt un caractère objectif et nécessaire, tandis que dans 
l'élaboration de Bouraoui elle acquiert une dimension subjective, axée autour d'une tension volontaire de l'individu. Entièrement joué sur le mode de la conciliation des contrastes, le transculturalisme bouraouien se révèle une approche efficace pour l'évolution du conflit engendré par le choc culturel, tant sur le plan de l'identité individuelle que sur ceux de la communication interculturelle et de l'expression littéraire.

$\mathrm{Au}$ contraire, si l'évolution transculturelle du multiculturalisme est demeurée à l'état d'utopie, c'est que le transculturalisme échappe à ce que Tassinari appelle « [...] la dictature du territoire. Le territoire transculturel embrasse l'ensemble de la terre » (Caccia, Sous le signe 301). La dimension sociopolitique du multiculturel implique un ancrage incontournable dans un territoire défini - ce qui pose une contradiction patente avec la dimension transversale de l'espace transculturel. Sa place de choix, ainsi que le démontre Bouraoui, c'est l'individu, en tant que sujet évolutif et sujet de communication, à même de tourner ses différentes identités en « identité de la différence ».

\section{Notes}

1. «Por aculturación se quiere significar el proceso de tránsito de una cultura a otra y sus repercusiones sociales de todo género. Pero transculturación es vocablo más apropriado. Hemos escogido el vocablo transculturación para expresar los variadísimos fenómenos que se originan en Cuba por las complejísimas transmutaciones de culturas que aquí se verifican, sin conocer las cuales es imposible entender la evolución del pueblo cubano [...]» (Ortiz 93).

2. Hédi Bouraoui a été parmi les collaborateurs du volume édité en 1992 par J.-M. Lacroix et F. Caccia, Métamorphoses d'une utopie, où figure son article intitulé « La troisième solitude ». Cet article a été ensuite repris par l'auteur dans son recueil d'essais Transpoétique (p. 113-120).

3. Régine Robin a bien remarqué que le projet transculturel, tout en étant politique dans son essence, ne l'était pas pour autant sur le plan de l'engagement politique : « il faut croire que les intellectuels du Québec n'étaient pas prêts à recevoir une pensée qui, prenant en écharpe le nationalisme traditionnel des intellectuels québécois, allait à l'encontre de leurs visées sans proposer quelque chose de précis. Nous n'étions pas un groupe politique, notre visée n'avait jamais été de choisir un camp politique. Notre force à nous était précisément de changer de terrain, de poser les problèmes autrement » (Robin 77). Pour une analyse détaillée de l'évolution du projet transculturel de Vice Versa par rapport au contexte québécois et canadien, cf. Tassinari p. 22-29.

4. «Dans cette quête, notre échec fut très productif. Même si nous n'avons pas été compris [...], nous avons développé une pensée qui a l'avenir pour elle dans tous les pays qui sont devenus peu ou prou des pays d'immigration » (Robin 77).

5. Il est opportun de rappeler ici la récurrence du mot utopie dans les titres des publications des fondateurs de Vice Versa, dont l'ouvrage collectif Métamorphoses d'une utopie, cité plus haut, et le recueil d'articles de L. Tassinari, Utopies par le hublot (Montréal: Carte Blanche, 1999). 
6. Dans son recueil d'essais publié en 2005, Bouraoui précise que « nous n'avons jamais lu Fernando Ortiz dont le nom nous a été mentionné en 2005. À sa lecture, la transcultura est un concept traitant l'anthropologie culturelle, l'hybridité de l'imposition pré-coloniale [...]. La transculturalité se définit comme le phénomène du passage d'une culture à l'autre. C'est la passerelle esthétique et culturelle qui facilite la communication d'une culture à l'autre. Encore une fois, rien à voir avec la problématique du colonialisme chez Fernando Ortiz » (Transpoétique 10-11).

7. Émigressence est le titre d'un des recueils poétiques de Bouraoui (Ottawa: Vermillon, 1992). C'est un mot-clé de la poétique bouraouienne qui pose l'essence de l'émigration en principe fondamental de création formelle et en thème majeur de l'œuvre.

8. Hédi Bouraoui a introduit ce néologisme dans son essai de civilisation comparée française et américaine, Créaculture I et II (Philadelphia/Montréal: CCD/Didier Canada, 1971).

9. Pour un approfondissement de ces thématiques, cf. Fernand Braudel, La Méditerranée. L'espace et l'histoire. Paris: Flammarion, 1985.

\section{Bibliographie}

Bernaus, Mercè, Ana Isabel Andrade, Martine Kervran, Anna Murkowska et Fernando Trujillo Sáez. La dimension plurilingue et pluriculturelle dans la formation des enseignants de langues. Strasbourg : Conseil de l'Europe, 2007.

Bouraoui, Hédi. Vers et l'Envers. Toronto : ECW Press, 1982.

« La troisième solitude. » Métamorphoses d'une utopie. Éd. Jean-Michel Lacroix et Fulvio Caccia. Paris-Montréal : Presses de la Sorbonne Nouvelle/Éditions Triptyque, 1992. p.175-183.

« Pertinence esthétique et éthique dans l'ensemble du champ poétique? » Carrefour de cultures. Mélanges offerts à Jacqueline Leiner. Éd. Régis Antoine. Tübingen : Gunter Narr Verlag, 1993. 49-56.

Bangkok blues. Ottawa : Vermillon, 1994.

La Francophonie à l'estomac. Paris : Nouvelles du Sud, 1995.

— Le mythe de l'orignalitude dans la praxis réelle d'une francophonie excentrée. » Francophonies d'Amérique. 10 (2000). 79-86.

— «Binarité infernale et transculturalisme. » Troisième Civilisation. 507 (2003). s. p.

_ Struga suivi de Margelle d'un festival. Montréal : Mémoire d'encrier, 2003.

Livr'errance. Mareuil sur Ourcq (France) : Éditions D'Ici et D'Ailleurs, 2005.

— Transpoétique. Éloge du nomadisme. Montréal : Mémoire d'encrier, 2005.

Caccia, Fulvio. Sous le signe du Phénix. Montréal : Guernica, 1985.

«Vice Versa, le Québec et le projet d'une république transculturelle. » Le projet transculturel de Vice Versa. Actes du Séminaire international du CISQ, Rome, 25 novembre 2005. Éd. Anna Paola Mossetto. Bologna : Pendragon, 2006. 31-41. Chamberland, François-Xavier. « Hédi Bouraoui. » L'Ontario se raconte. De A à X. Entrevues radiophoniques. Toronto : Éditions du Gref, 1999. 183-188.

Conseil de l'Europe. Cadre européen commun de référence pour les langues.

Strasbourg-Paris : Conseil de l'Europe/Éditions Didier, 2001.

Dotoli, Giovanni. «Entretien avec Hédi Bouraoui. » Culture et littérature canadiennes de langue française. Éd. Giovanni Dotoli. Fasano (Italie) : Schena, 2003. 49-64. 
Falcicchio, Adriana. « Entretien avec Hédi Bouraoui. » Rivista di Studi Canadesi. 17 (2004) : 117-137.

Grand Robert de la langue française. Éd. Alain Rey. Paris : Le Robert, 2011.

Lamore, Jean. «Transculturation : Naissance d'un mot. » Métamorphoses d'une utopie. Éd. Jean-Michel Lacroix et Fulvio Caccia. Paris-Montréal : Presses de la Sorbonne Nouvelle/Éditions Triptyque, 1992. 43-48.

Lacroix, Jean-Michel, Caccia, Fulvio, Éd. Métamorphoses d'une utopie. ParisMontréal : Presses de la Sorbonne Nouvelle/Éditions Triptyque, 1992.

Moisan, Clément, Hildebrand, Renate. Ces étrangers du dedans. Une histoire de l'écriture migrante au Québec (1937-1997). Québec : Éditions Nota bene, 2001.

Ortiz, Fernando. Contrapunteo cubano del tabaco y el azúcar. Caracas : Biblioteca Ayacucho, 1978 [1940].

Petit Larousse. Éd. Philippe Merlet et Anémone Berès. Paris : Éditions Larousse, 2003.

Petit Larousse en ligne. Éd. Isabelle Jeuge-Maynart. www.larousse.fr. Paris : Éditions Larousse, 2009.

Rimbaud, Arthur. Poésies. Une saison en enfer. Illuminations. Éd. Louis Forestier. Paris : Gallimard, 1984.

Robin, Régine. «Vice Versa, un échec productif. » Le projet transculturel de Vice Versa. Actes du Séminaire international du CISQ, Rome, 25 novembre 2005. Éd. Anna Paola Mossetto. Bologna : Pendragon, 2006. 67-80.

Tassinari, Lamberto. « Sens de la transculture. » Le projet transculturel de Vice Versa. Actes du Séminaire international du CISQ, Rome, 25 novembre 2005. Éd. Anna Paola Mossetto. Bologna : Pendragon, 2006. 17-29. 